\title{
Association between Serum Antibody Titers against Influenza Viruses and the Risk of Influenza in Patients with Chronic Respiratory Diseases - a Prospective, Longitudinal Study
}

\author{
Nandhini P', Sujatha Sistla ${ }^{2}, \underline{\text { Kadhiravan Tamilarasu }}{ }^{3}$
}

${ }^{1}$ Research Scholar, ${ }^{2}$ Professor, Department of Microbiology, Jawaharlal Institute of Postgraduate Medical Education and Research (JIPMER), Puducherry, India.

${ }^{3}$ Professor, Department of Medicine, Jawaharlal Institute of Postgraduate Medical Education and Research (JIPMER), Puducherry, India.

DOI: https://doi.org/10.24321/0019.5138.202140

\section{I $\quad \mathbf{N} \quad \mathbf{F} \quad \mathbf{O}$}

\section{Corresponding Author:}

Sujatha Sistla, Department of Microbiology, Jawaharlal Institute of Postgraduate Medical Education and Research (JIPMER), Puducherry, India.

E-mail Id:

sujathasistla@gmail.com

Orcid Id:

https://orcid.org/0000-0002-4286-6908

How to cite this article:

Nandhini P, Sistla S, Tamilarasu K. Association between Serum Antibody Titers against Influenza Viruses and the Risk of Influenza in Patients with Chronic Respiratory Diseases - a Prospective, Longitudinal Study. J Commun Dis. 2021;53(3):6975 .

Date of Submission: 2021-06-04

Date of Acceptance: 2021-09-25

\section{$\begin{array}{llllllll}\mathbf{A} & \mathbf{B} & \mathbf{S} & \mathbf{T} & \mathbf{R} & \mathbf{A} & \mathbf{C} & \mathbf{T}\end{array}$}

Introduction: Patients with respiratory co-morbidities are the primary target group for influenza vaccination as chronic respiratory diseases pose a serious risk for unvaccinated individuals during influenza season. According to Centers for Disease Control and Prevention (CDC) guidelines, serum antibody titer of $\geq 40$ is associated with "at least a $50 \%$ decrease in risk of acquiring influenza infection".

Methods: A prospective, longitudinal study was conducted in 345 patients with chronic respiratory diseases (April 2014-August 2015). Serum samples were tested for antibody levels against influenza $A$ and $B$ viruses using hemagglutination inhibition assay as per WHO protocol. These patients were followed up for one year and nasopharyngeal swab was collected from any patient who reported Influenza-like illness symptoms and subjected to real-time PCR for influenza viruses.

Results: The seroprotective rates against influenza $A$ (H1N1) pdm09, influenza $A(H 3 N 2)$, influenza B (Victoria and Yamagata) were $61 \%, 94 \%$, $61 \%, 68 \%$ respectively. During the follow-up period of one year, 5 cases of influenza $A / H 3 N 2$ and 7 cases of influenza $B$ infection were identified while there were no cases of influenza $A(H 1 N 1) p d m 09$ infection. One case of influenza $\mathrm{A} / \mathrm{H} 3 \mathrm{~N} 2$ infection was observed in an individual who had protective titers against the same virus while all 7 cases of influenza $B$ infection occurred in people with non-protective titers against both the strains of influenza $B$ viruses.

Conclusion: Based on the findings of this study, it is proposed that in patients with chronic respiratory diseases influenza vaccination may be considered after more concrete information is obtained on correlates of protection against influenza subtypes.

Keywords: Influenza, Seroepidemiology, High-Risk Patients, Vaccine 


\section{Introduction}

Acute respiratory infections are a leading cause of hospitalization of patients with underlying chronic respiratory conditions like Bronchial Asthma (BA), chronic obstructive pulmonary disease (COPD) and cystic fibrosis; elderly; pregnant women; children; and obese individuals. Infection with influenza is an important cause of excess mortality and morbidity in these high-risk groups and may affect the progression of the disease. ${ }^{1}$ According to CDC, the individuals in high-risk groups are more likely to develop severe disease following influenza infection leading to complications that necessitate hospitalization and sometimes death. ${ }^{2}$

Globally, influenza is currently caused by three viruses namely influenza $A$ (H1N1), influenza $A(H 3 N 2)$ and influenza $B$, of these, influenza $A$ virus has potential to cause pandemics like the novel 2009 influenza A (H1N1) pandemic. WHO declared post-pandemic period in August 2010. However, reports of sporadic influenza cases associated with mortality are still being documented across the country. The currently available influenza vaccine affords protection against all the three influenza viruses and is recommended as an annual vaccine in western countries for the high- risk groups. ${ }^{3}$

In India, there is a lack of consensus regarding the need for annual influenza vaccination for the patients with chronic respiratory diseases for several reasons - one of them being a lack of reliable local data on the risk of influenza infection among these individuals to inform policy making. ${ }^{4}$ As per Association of Physicians of India (API) guidelines, the use of influenza vaccine is not recommended in India due to the absence of epidemiological surveillance data on different serotypes in the country. Additionally, it clarifies that "there is no evidence to recommend the use of influenza vaccine in patients with chronic health conditions". ${ }^{5}$

Serological data may provide useful information about influenza burden and population immunity. ${ }^{6}$ Haemagglutination Inhibition (HI Hemagglutination inhibition assay (HAl) is one of the simple and inexpensive serological techniques for measuring influenza-specific antibodies in the serum and this antibody titer has been correlated with protective immunity in humans. Serum antibody titer of greater than or equal to 40 is associated with "at least a $50 \%$ decrease in risk of acquiring influenza infection" according to CDC guidelines, MMWR, 2009. ${ }^{7}$ However, there is no local data to correlate the protective status obtained in the HAl studies and episodes of influenza infection in these patients.

Hence, the objective of this study was to measure the seropositivity rates to influenza $A$ and $B$ viruses in the patients with chronic respiratory diseases. Additionally, these patients were followed up for a period of one year to determine the proportion of patients (with or without seroprotective status) who contract influenza during the subsequent influenza season in order to obtain data which would indicate the need for routine annual vaccination in this group.

\section{Materials and Methods}

\section{Study Design}

\section{Patients with Chronic Respiratory Diseases}

A prospective, longitudinal study was conducted from April 2014-August 2015. Sample size of 345 was derived with frequency of outcome factor $33 \%$ \& absolute precision of $5 \%$ and $\mathrm{Cl}$ of $95 \%$ using OpenEpisoftware (version 3.03a). ${ }^{8}$ more than half of patients with chronic obstructive pulmonary disease (COPD Adults (aged 18 years or more) with chronic respiratory diseases such as bronchial asthma (BA), COPD, bronchiectasis attending the respiratory clinic, Department of Medicine, JIPMER hospital for a period of 1 year and above were included. Patients on immunosuppressive drugs such as systemic corticosteroids were excluded (although inhaled steroids were not a basis for exclusion). All the requisite samples were collected between April and August 2014. Each of these patients was followed up for a year with the follow-up period coming to an end in August 2015. The study was approved by the Institute Human Ethics Committee.

\section{Data and Specimen Collection}

After obtaining written informed consent, patient information was recorded. By applying the tourniquet, 3-5 $\mathrm{mL}$ blood was collected using a $5 \mathrm{~mL}$ syringe. The collected blood was kept in a test tube at room temperature for 30 40 minutes. Blood samples were centrifuged to separate the serum component. Until further testing, these serum samples were stored at $-80^{\circ} \mathrm{C}$.

\section{Laboratory Procedures}

\section{Antigens}

WHO control antigens used in HAI on serum of patients with chronic respiratory diseases:

- Influenza A (H1N1) pdm09 Control Antigen (A/ California/ 07/2009 NYMC X-179A), BPL-Inactivated

- Influenza A(H3N2) Control Antigen (A/Victoria/361/2011 IVR-165), BPL-Inactivated

- Influenza B Control Antigen, Yamagata Lineage (B/ Wisconsin/1/2010 BX-41A), BPL-Inactivated

- Antigens-Influenza B virus--Influenza B Control Antigen, Victoria Lineage (B/Brisbane/60/2008), BPL-Inactivated

Hemagglutination Titration and Hemagglutination Inhibition Assay

Serum samples were treated using RDE (Vibrio cholerae 
neuraminidase) to remove the non-specific inhibitors. RDE-treated samples were subjected to HA titration and hemagglutination inhibition assay as per WHO protocol.

\section{Influenza Real-time PCR}

As the part of the secondary objective of seroepidemiology study in patients with chronic respiratory diseases, during the one-year follow-up period, a nasopharyngeal swab was collected from any patient among the study population who reported Influenza-like illness symptoms and subjected to real-time PCR for influenza A and B viruses.

\section{Statistical Analysis}

Data obtained from the questionnaire were loaded into Microsoft Excel 2007 and then exported to SPSS version 17 for analysis. Association of seropositive status with occupation, gender, age, vaccination status, history of influenza infection was tested using chi-square test. Association between protective titres and lab-confirmed influenza was tested by chi-square test. P-value of less than 0.05 was considered to be significant.

\section{Results}

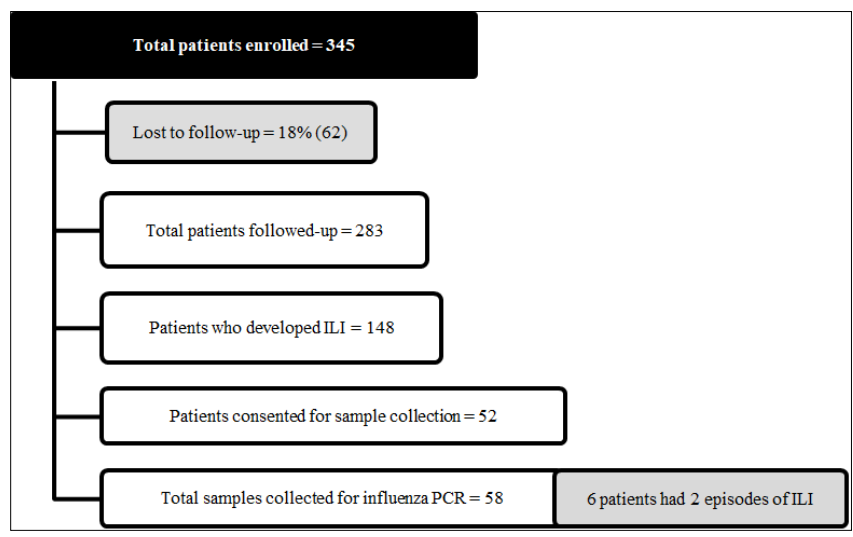

Figure I.Flowchart for Enrolment and Follow-up of Patients with Chronic Respiratory Diseases

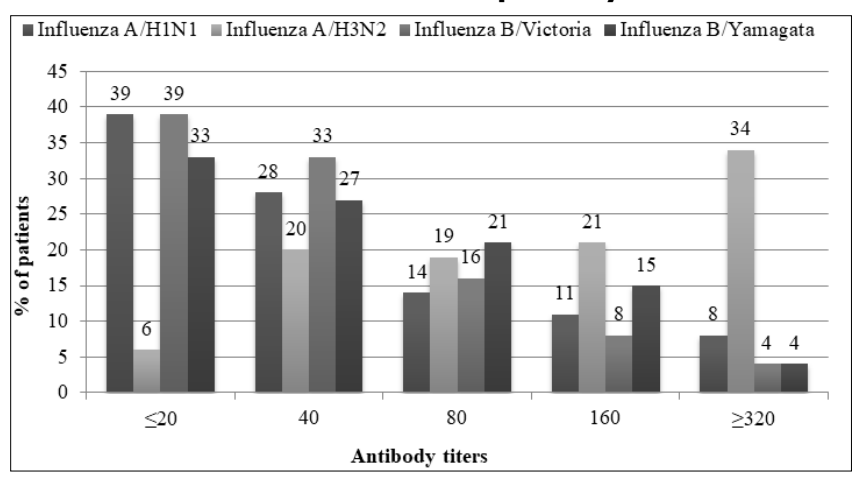

Figure 2.Seropositivity to Influenza in Patients with Chronic Respiratory Diseases

\section{Seroepidemiology in Patients with Chronic Respiratory Diseases}

A total of 345 consecutive patients with chronic respiratory diseases were enrolled in this study between April 2014 and August 2015 (Figure 1). Patients' characteristics are given in Table 1. Among 345 patients, 328 (95\%) had bronchial asthma and 17 (5\%) had COPD. The mean age of the patients $=50.64$ years and more than $60 \%$ were females and about $50 \%$ of the patients were in age group of 41-60 years. Three-fourths of the patients were from the rural part of Puducherry (75\%). Only $2 \%$ of the patients had taken influenza vaccination in the previous years. Most of the patients $(77 \%)$ had no contact with known cases of influenza.

Table I.Characteristics of Patients with Chronic Respiratory Diseases

\begin{tabular}{|l|c|}
\hline \multicolumn{2}{|c|}{$(\mathbf{n}=345)$} \\
\hline Characteristics & $\mathbf{n}(\%)$ \\
\hline Type of illness \\
\hline BA & $328(95)$ \\
\hline COPD & $17(5)$ \\
\hline
\end{tabular}

Age group (in years)

\begin{tabular}{|c|c|}
\hline $18-40$ & $95(28)$ \\
\hline $41-60$ & $173(50)$ \\
\hline $61-90$ & $77(22)$ \\
\hline
\end{tabular}

Gender

\begin{tabular}{|c|c|}
\hline Female & $228(66)$ \\
\hline Male & $117(34)$ \\
\hline \multicolumn{2}{|l|}{ Residence } \\
\hline Rural & $260(75)$ \\
\hline Urban & $85(25)$ \\
\hline \multicolumn{2}{|c|}{ Domestic fuel used for cooking } \\
\hline LPG & $143(41)$ \\
\hline Bio-mass fuel & $99(29)$ \\
\hline Both & $103(30)$ \\
\hline
\end{tabular}

Usage of inhaled steroids

\begin{tabular}{|c|c|}
\hline Yes & $60(17)$ \\
\hline No & $285(83)$ \\
\hline \multicolumn{2}{|c|}{ Influenza vaccination } \\
\hline Yes & $7(2)$ \\
\hline No & $338(98)$ \\
\hline
\end{tabular}

Family history of chronic illness

\begin{tabular}{|c|c|}
\hline Yes & $78(23)$ \\
\hline No & $267(77)$ \\
\hline \multicolumn{2}{|c|}{ Occupation } \\
\hline Farmers & $87(25)$ \\
\hline Housewives & $114(33)$ \\
\hline Daily labourers & $76(22)$ \\
\hline
\end{tabular}




\begin{tabular}{|c|c|}
\hline Students & $6(2)$ \\
\hline Professionals & $20(6)$ \\
\hline Nil & $42(12)$ \\
\hline Diabetes mellitus & $16(5)$ \\
\hline Hypertension & $43(12)$ \\
\hline Both & $8(2)$ \\
\hline Smokers & $42(12)$ \\
\hline $\begin{array}{c}\text { Patients with history of hospital } \\
\text { admission due to chronic illness }\end{array}$ & $106(31)$ \\
\hline $\begin{array}{c}\text { Patients with history of known (lab- } \\
\text { confirmed) influenza infection }\end{array}$ & 0 \\
\hline
\end{tabular}

Table 2.Geometric Mean Titre and Seroprotection Rate among Patients with Chronic Respiratory Diseases

\begin{tabular}{|c|c|}
\hline \multicolumn{2}{|c|}{ Patients with chronic respiratory diseases } \\
\hline Geometric mean titer \\
\hline A/California/07/2009 (H1N1) & 39.04 \\
\hline A/Victoria/361/2011 (H3N2) & 132.16 \\
\hline Influenza /Wisconsin/1/2010* & 42.83 \\
\hline Influenza /Brisbane/60/2008\# & 35.38 \\
\hline Seroprotection rate (\%) \\
\hline A/California/07/2009 (H1N1) & $61 \%$ \\
\hline A/Victoria/361/2011 (H3N2) & $94 \%$ \\
\hline Influenza /Wisconsin/1/2010* & $68 \%$ \\
\hline Influenza /Brisbane/60/2008\# & $61 \%$ \\
\hline \multicolumn{2}{|c|}{$*$ Yamagata lineage, \#Victoria lineage. } \\
\hline
\end{tabular}

The seroprotective rates against pandemic influenza $A(H 1 N 1) p d m 09$, influenza A (H3N2), influenza B/Victoria and influenza $\mathrm{B}$ /Yamagata among patients with chronic respiratory diseases were $61 \%, 94 \%, 61 \%, 68 \%$ respectively (Table $2 \&$ Figure 2). No association was found between the antibody titres and type or duration of illness, gender, age groups, habit of smoking, diabetes mellitus/ hypertension, residence (rural/ urban), occupation and use of inhaled steroids (Table 3).

Table 3.Seropositivity to Influenza Antigens among Patients with Chronic Respiratory Diseases

$(n=345)$

\begin{tabular}{|c|c|c|c|c|}
\hline \multirow{2}{*}{ Characteristics } & \multicolumn{4}{|c|}{ Seropositives, $\mathbf{n}$ (\%) } \\
\cline { 2 - 5 } & $\begin{array}{c}\text { A } \\
\text { (H1N1) }\end{array}$ & $\begin{array}{c}\text { A } \\
\text { (H3N2) }\end{array}$ & $\begin{array}{c}\text { B } \\
\text { (Victoria) }\end{array}$ & $\begin{array}{c}\text { B (Yama- } \\
\text { gata) }\end{array}$ \\
\hline Type of illness \\
\hline BA (328) & $\begin{array}{c}202 \\
(62)\end{array}$ & $\begin{array}{c}309 \\
(94)\end{array}$ & $202(62)$ & $223(68)$ \\
\hline COPD (17) & $9(53)$ & $15(88)$ & $8(47)$ & $10(59)$ \\
\hline
\end{tabular}

\begin{tabular}{|l|c|c|c|c|}
\hline \multicolumn{1}{|c|}{ Duration of illness } \\
\hline $\begin{array}{c}1-5 \text { years } \\
(167)\end{array}$ & $\begin{array}{c}107 \\
(64)\end{array}$ & $\begin{array}{c}158 \\
(95)\end{array}$ & $105(63)$ & $107(64)$ \\
\hline $\begin{array}{c}6-20 \text { years } \\
(163)\end{array}$ & $95(58)$ & $\begin{array}{c}152 \\
(93)\end{array}$ & $98(60)$ & $118(72)$ \\
\hline$>20$ years (15) & $9(60)$ & $14(93)$ & $7(47)$ & $8(53)$ \\
\hline Age group \\
\hline $\begin{array}{c}18-40 \text { years } \\
(95)\end{array}$ & $55(58)$ & $90(95)$ & $62(65)$ & $68(72)$ \\
\hline $\begin{array}{c}41-60 \text { years } \\
(173)\end{array}$ & $\begin{array}{c}112 \\
(65)\end{array}$ & $\begin{array}{c}161 \\
(93)\end{array}$ & $110(64)$ & $112(65)$ \\
\hline $\begin{array}{c}61-90 \text { years } \\
(77)\end{array}$ & $44(57)$ & $73(95)$ & $38(49)$ & $53(69)$ \\
\hline Community
\end{tabular}

\begin{tabular}{|c|c|c|c|c|}
\hline Community \\
\hline Rural (260) & $\begin{array}{c}156 \\
(60)\end{array}$ & $\begin{array}{c}244 \\
(94)\end{array}$ & $158(61)$ & $177(68)$ \\
\hline Urban (85) & $55(65)$ & $80(94)$ & $52(61)$ & $56(66)$ \\
\hline
\end{tabular}

\section{Gender}

\begin{tabular}{|c|c|c|c|c|}
\hline Female (228) & $\begin{array}{c}144 \\
(63)\end{array}$ & $\begin{array}{c}212 \\
(93)\end{array}$ & $140(61)$ & $150(66)$ \\
\hline Male (117) & $67(57)$ & $\begin{array}{c}112 \\
(96)\end{array}$ & $70(60)$ & $83(71)$ \\
\hline Smokers (42) & $28(67)$ & $41(98)$ & $26(62)$ & $30(71)$ \\
\hline $\begin{array}{c}\text { Diabetic/ } \\
\text { hypertension } \\
(67)\end{array}$ & $42(63)$ & $64(96)$ & $37(55)$ & $37(55)$ \\
\hline
\end{tabular}

\section{Occupation}

\begin{tabular}{|c|c|c|c|c|}
\hline $\begin{array}{c}\text { Housewives } \\
(114)\end{array}$ & $70(61)$ & $\begin{array}{c}105 \\
(92)\end{array}$ & $71(62)$ & $70(61)$ \\
\hline Farmers (87) & $58(67)$ & $84(97)$ & $54(62)$ & $61(70)$ \\
\hline $\begin{array}{c}\text { Usage of } \\
\text { inhaled } \\
\text { steroids (60) }\end{array}$ & $38(63)$ & $57(95)$ & $39(65)$ & $40(67)$ \\
\hline
\end{tabular}

*Chi-square - no significance observed between seropositive groups.

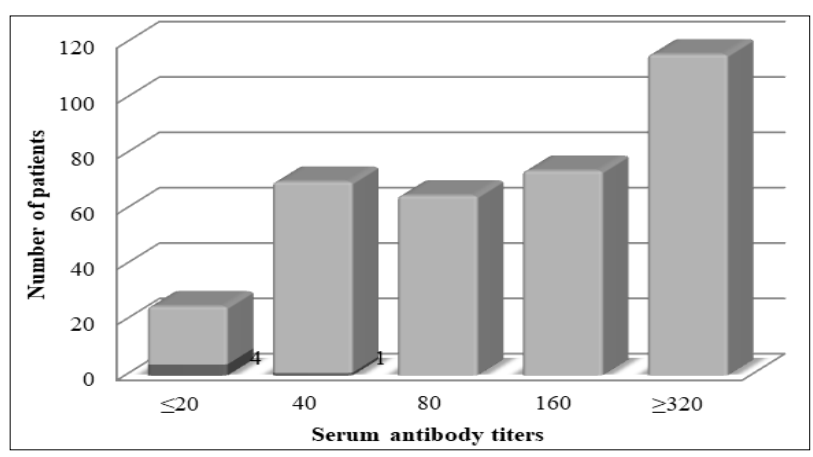

Figure 3.Relationship between Serum Antibody Titers and the Occurrence of Influenza A/H3N2 Infection in Patients with Chronic Respiratory Diseases 
The bars indicates the number of patients with real-time PCR-confirmed influenza $A / H 3 N 2$ infection. Chi square $p$ value $<0.05$, ODDs ratio for influenza $A / H 3 N 2=0.01(95 \%$ $\mathrm{Cl}$ 0.0014-0.1242).

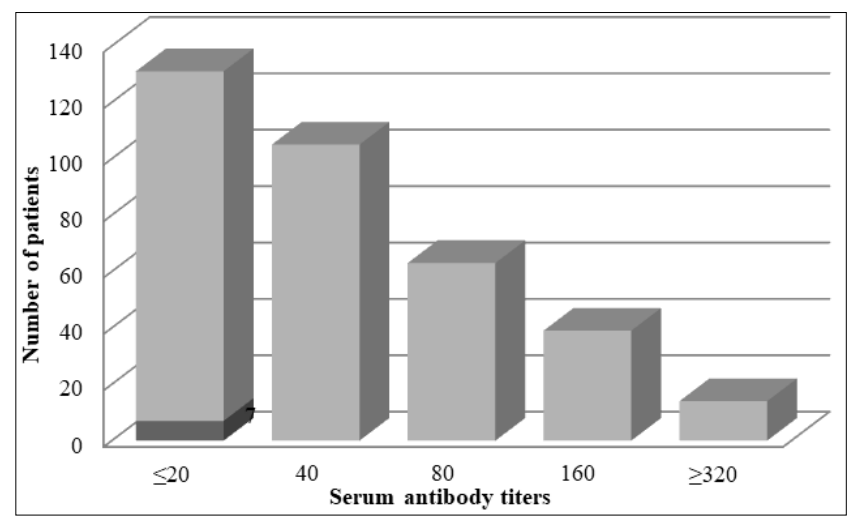

Figure 4.Relationship between Serum Antibody Titers and the Occurrence of Influenza B Infection in Patients with Chronic Respiratory Diseases

The bar indicates the number of patients with real-time PCR-confirmed influenza B infection. Chi-square $p$-value < 0.05 , ODDs for Influenza $B=0$.

The mean duration of follow-up months was 13.79 months (95\% $\mathrm{Cl}=13.65-13.94)$. The influenza virus detection using real-time PCR identified 5 cases of influenza A/H3N2 and 7 cases of influenza $B$ infection while there were no cases of influenza $A(H 1 N 1) p d m 09$ infection reported in this study population. One case of influenza A/H3N2 infection was observed in an individual who had protective titers against the same virus while all 7 cases of influenza B infection occurred in people with non-protective titers against both the strains of influenza B viruses (influenza B/ Victoria and influenza B/ Yamagata) (Figures 3 \& 4). The influenza infections caused by both influenza A/H3N2 and influenza $B$ in these 12 patients were mild.

\section{Discussion}

Patients with respiratory co-morbidities are the primary target group for influenza vaccination in the developed countries as chronic respiratory diseases pose a serious risk for unvaccinated individuals during influenza season. ${ }^{9}$ Influenza is known to create severe complications in patients with bronchial asthma and COPD. ${ }^{10-12}$ in population-based studies it has been difficult to separate the effects of influenzavirus from those of respiratory syncytial virus. Respiratory syncytial virus often circulates with influenzaviruses and is the most frequent cause of hospitalization for lower respiratory tract infections in infants and young children. We studied the rates of hospitalization for acute respiratory-disease among infants and children during periods when the circulation of influenzaviruses predominated over the circulation of respiratory syncytial virus. For each season from October to May during the period from 1992 to 1997 , we used local viral surveillance data to define periods in Washington State and northern California when the circulation of influenzaviruses predominated over that of respiratory syncytial virus. We calculated the rates of hospitalization for acute respiratory disease, excess rates attributable to influenzavirus, and incidence-rate ratios for all infants and children younger than 18 years of age who were enrolled in either the Kaiser Permanente Medical Care Program of Northern California or the Group Health Cooperative of Puget Sound. The rates of hospitalization for acute respiratory disease among children who did not have conditions that put them at high risk for complications of influenza (e.g., asthma, cardiovascular diseases, or premature birth In 2007, PlansRubió et al. reported $>30 \%$ increase in case fatality in COPD patients during influenza A epidemics. ${ }^{8}$ More than half of patients with chronic obstructive pulmonary disease (COPD Influenza is also known to cause severe asthma exacerbations, particularly in adults. ${ }^{13}$ Influenza virus is a particularly important pathogen due to its enormous morbidity and mortality in annual epidemics. The swineorigin influenza $A$ virus, designated as $A(H 1 N 1) .{ }^{14}$

In this study, conducted between April 2014 and August 2015 , the seropositivity rates against influenza viruses among patients with chronic respiratory diseases were $>60 \%$. A pilot study conducted by us among health care workers in the same geographical region showed $>80 \%$ seropositivity rates against influenza viruses. ${ }^{15}$ High seropositivity rates were observed in both these studies; however this finding can have two possible interpretations. On the one hand, it may indicate that these patients may be protected against subsequent influenza infection due to the pre-existing protective antibody levels. On the contrary, higher rates of serum antibodies against influenza viruses also indicate that this group is repeatedly exposed to these viruses suggesting a greater risk of acquiring the infection in case of an outbreak. Reports exist in literature to support both points of view. ${ }^{16,17}$

About $31 \%$ of the patients with chronic respiratory diseases had been admitted in previous years due to worsening of the chronic illness; there was no association of serum antibody titers against any of the influenza viruses ( $p$-value $>0.2$ ) and no one reported a history of known influenza infection. This shows probable absence of severe influenza infection, although mild/ subclinical infection might have occurred in these patients. Only $2 \%$ of the patients with chronic respiratory diseases had received influenza vaccination and it underlines the fact that despite the high recommendation, the vaccination rate remains low in these high-risk patients. ${ }^{18}$ The reasons behind low vaccine coverage could be the following: First, the study patients had not been affected by severe influenza infection so as 
to become aware of the influenza-related complications; second, there is a dilemma among physicians regarding the efficacy and safety of influenza vaccines to mandate this vaccination in patients with chronic diseases. Third, since these patients were mostly from rural regions (75\%), with below poverty line status, their access and willingness to spend on an expensive annual influenza vaccine each year may be limited.

Seropositivity rates to influenza viruses did not differ with the type or duration of the chronic respiratory condition. In a study from Spain, which assessed the risk factors associated with influenza $A(H 1 N 1) p d m 09$ hospitalisation, the authors found the manual workers and patients with COPD are at increased risk of acquiring influenza complications. ${ }^{19}$ However, in our study, no difference was found in the serum antibody titers based on the type of chronic illness and professional class. Occupational dust, chemicals and use of solid fuels for cooking are considered as risk factors for chronic lung diseases and biomass fuel exposure has been associated with different respiratory disease particularly in rural population. ${ }^{20}$ In our study, $>50 \%$ of the patients in our study used solid fuels for cooking, but the seropositivity rates did not differ when with other patients. As systemic steroids are known to restrain immune responses, including antibody production, only patients on inhaled steroids were included in the study; however, no difference was found in the seropositivity levels among users and non-users of the same.

Serum antibody titers against HA component of influenza viruses has been demonstrated as a predictor of immune protection against influenza infection. ${ }^{21}$ Determination of the role of serum antibody levels in protection against influenza in patients with chronic respiratory diseases was complicated due to a small number of laboratory-confirmed influenza cases during the study period. Due to an outbreak of influenza $A(H 1 N 1) p d m 09$ in Puducherry during early 2015 , influenza $B$ and influenza $A / H 3 N 2$ cases were low in the general population and also in patients with chronic respiratory diseases. ${ }^{22}$ There were 5 and 7 cases of influenza A/H3N2 and influenza B infection respectively; all were mild. One case of influenza $A / H 3 N 2$ infection was observed in an individual who had protective titers against the same virus and 7 cases of influenza B infection in persons with non-protective titers against both the strains of influenza $B$ viruses (influenza B/ Victoria and influenza B/ Yamagata). Statistically, patients with protective titers against influenza $\mathrm{A}(\mathrm{H} 3 \mathrm{~N} 2)$ and influenza $B$ had low risk and no risk of acquiring the respective infection respectively.

Although more than $30 \%$ of the patients with chronic respiratory diseases were not protected against pandemic influenza $A(H 1 N 1) p d m 09$ virus, during the follow-up of one year, no influenza $A(H 1 N 1) p d m 09$ cases were observed in the study population although there was an ongoing outbreak in the general population. ${ }^{22}$ This is contradictory to reports showing increased influenza $A(H 1 N 1)$ infection in patients with lower serum antibody titers..$^{23}$ It is possible that a few patients developed severe respiratory disease caused by influenza and died without hospital care and hence were lost to follow-up. Although we are yet to explore it scientifically, the failure to report to the hospital with the mild respiratory infection in these patients who suffer from chronic respiratory illness for many years should be considered.

The main limitation of this study is that there were only few mild cases of influenza infections reported by patients in the follow up of one year and it was not extended to more years. However, this is one of the first prospective Indian study which reported antibody titers and follow up infection status of the all the three most common influenza viruses, influenza $A(H 1 N 1) p d m 09$, influenza $A$ / H3N2 and influenza $B$ viruses among the patients with chronic respiratory diseases. The correlations of yearly analysis of antibody titers against influenza viruses with infections at least in the high risk groups including patients with chronic diseases, immunocompromised status, and congenital disorders can be an effective data to decide on the need of the influenza annual vaccination among these high risk population.

\section{Conclusion}

Despite nearly $30 \%$ of the study population with chronic diseases had non-protective serum antibody titers against influenza $A(H 1 N 1) p d m 09$, none of the patients developed the infection during the follow up period, however the seroprotective rates correlated in case of influenza $B$ infection. The serum protective titers against influenza subtypes were not linked to vaccination as only $2 \%$ of the participants had taken prior annual influenza vaccination. Hence it is proposed that in patients with chronic respiratory diseases influenza vaccination may be considered after a more concrete information is obtained on correlates of protection against influenza using larger, communitybased studies.

\section{Acknowledgements}

We thank CDC- International Reagent Resource (IRR) for providing influenza antigens and antibodies. We thank DST-INSPIRE, National Centre for Disease Control (NCDC) and Integrated Disease Surveillance Programme (IDSP), New Delhi for financial support.

\section{Conflict of Interest: None}

\section{References}

1. Rothbarth PH, Kempen BM, Sprenger MJW. Sense and nonsense of influenza vaccination in asthma and 
chronic obstructive pulmonary disease. Am J Respir Crit Care Med. 1995;151(5):1682-6. [PubMed) [Google Scholar)

2. CDC [Internet). People at high risk of developing flurelated complications. Seasonal Influenza (Flu): CDC; [2016 Aug 6). Available from: http://www.cdc.gov/flu/ about/disease/high_risk.html

3. CDC [Internet). People at high risk of flu; 2021 [cited 2021 Sep 27). Available from: https://www.cdc.gov/ flu/highrisk/index.html

4. Vashishtha VM, Kalra A, Choudhury P. Influenza vaccination in India: Position paper of Indian Academy of Pediatrics, 2013. Indian Pediatr. 2013 Sep;50(9):86774. [PubMed] [Google Scholar]

5. Expert Group of the Association of Physicians of India on Adult Immunization in India. The Association of Physicians of India evidence-based clinical practice guidelines on adult immunization. J Assoc Physicians India. 2009 Apr;57:345-56. [PubMed] [Google Scholar]

6. Yeolekar LR, Kulkarni PB, Chadha MS, Rao BL. Seroepidemiology of influenza in Pune, India. Indian J Med Res. 2001;114:121-6. [Google Scholar]

7. Centers for Disease Control and Prevention (CDC). Serum cross-reactive antibody response to a novel influenza $A$ (H1N1) virus after vaccination with seasonal influenza vaccine. MMWR Morb Mortal Wkly Rep. 2009 May;58(19):521-4. [PubMed] [Google Scholar]

8. Plans-Rubió P. Prevention and control of influenza in persons with chronic obstructive pulmonary disease. Int J Chron Obstruct Pulmon Dis. 2007;2(1):41-53. [PubMed] [Google Scholar]

9. Grohskopf LA, Sokolow LZ, Olsen SJ, Bresee JS, Broder $K R$, Karron RA. Prevention and control of influenza with vaccines: recommendations of the advisory committee on immunization practices, United States, 2015-16 influenza season. MMWR Morb Mortal Wkly Rep. 2015 Aug;64(30):818-25. [PubMed] [Google Scholar]

10. Izurieta HS, Thompson WW, Kramarz P, Shay DK, Davis RL, DeStefano F, Black S, Shinefield H, Fukuda K. Influenza and the rates of hospitalization for respiratory disease among infants and young children. N Engl J Med. 2000 Jan;342(4):232-9. [PubMed] [Google Scholar]

11. Neuzil KM, Mellen BG, Wright PF, Mitchel EF, Griffin MR. The effect of influenza on hospitalizations, outpatient visits, and courses of antibiotics in children. N Engl J Med. 2000 Jan;342(4):225-231. [PubMed] [Google Scholar]

12. Cates CJ, Rowe BH. Vaccines for preventing influenza in people with asthma. Cochrane Database Syst Rev. 2013 Feb;2:CD000364. [PubMed] [Google Scholar]

13. Obuchi M, Adachi Y, Takizawa T, Sata T. Influenza $A(H 1 N 1) p d m 09$ virus and asthma. Front Microbiol.
2013 Oct;4:1-5. [PubMed] [Google Scholar]

14. Papadopoulos NG, Christodoulou I, Rohde G, Agache I, Almqvist C, Bruno A, Bonini S, Bont L, Bossios A, Bousquet J, Braido F, Brusselle G, Canonica GW, Carlsen KH, Chanez P, Fokkens WJ, Garcia-Garcia M, Gjomarkaj M, Haahtela T, Holgate ST, Johnston SL, Konstantinou G, Kowalski M, Lewandowska-Polak A, Lødrup-Carlsen K, Mäkelä M, Malkusova I, Mullol J, Nieto A, Eller E, Ozdemir C, Panzner P, Popov T, Psarras S, Roumpedaki E, Rukhadze M, Stipic-Markovic A, Todo Bom A, Toskala $E$, van Cauwenberge $P$, van Drunen $C$, Watelet JB, Xatzipsalti M, Xepapadaki P, Zuberbier T. Viruses and bacteria in acute asthma exacerbations-a GA2 LENDARE systematic review. Allergy. 2011 Apr;66(4):45868. [PubMed] [Google Scholar]

15. Nandhini G, Sujatha S. Seropositivity to influenza $A(H 1 N 1) p d m 09$ and influenza $A(H 3 N 2)$ and risk of infection in health care workers. Clin Epidemiol Glob Health. 2016;4(1):28-32. [Google Scholar]

16. Costantino C, Vitale F. Influenza vaccination in high-risk groups: a revision of existing guidelines and rationale for an evidence-based preventive strategy. J Prev Med Hyg. 2016;57(1):E13-8. [PubMed] [Google Scholar]

17. Couch RB, Atmar RL, Franco LM, Quarles JM, Wells J, Arden N, Niño D, Belmont JW. Antibody correlates and predictors of immunity to naturally occurring influenza in humans and the importance of antibody to the neuraminidase. J Infect Dis. 2013 Mar;207(6):974-81. [PubMed] [Google Scholar]

18. Pujol J, Godoy P, Soldevila N, Castilla J, GonzálezCandelas F, Mayoral JM, Astray J, Garcia S, Martin V, Tamames S, Delgado M, Domínguez A; CIBERESP Cases and Controls in Pandemic Influenza Working Group. Social class based on occupation is associated with hospitalization for $\mathrm{A}(\mathrm{H} 1 \mathrm{~N} 1)$ pdm09 infection. Comparison between hospitalized and ambulatory cases. Epidemiol Infect. 2016 Mar;144(4):732-40. [PubMed] [Google Scholar]

19. Po JY, FitzGerald JM, Carlsten C. Respiratory disease associated with solid biomass fuel exposure in rural women and children: systematic review and metaanalysis. Thorax. 2011 Mar;66(3):232-9. [PubMed] [Google Scholar]

20. Nandhini G, Sujatha S. Epidemiology of influenza viruses from 2009 to 2013 - A sentinel surveillance report from Union territory of Puducherry, India. Asian Pac J Trop Med. 2015 Sep;8(9):718-23. [PubMed] [Google Scholar]

21. Wong SS, Yuen K-Y. Antiviral therapy for respiratory tract infections. Respirology. 2008 Nov;13(7):950-71. [PubMed] [Google Scholar] 